\title{
A MATEMÁTICA ESCOLAR E O LABORATÓRIO COMO AMBIENTE DE APRENDIZAGEM: ALGUMAS CONSIDERAÇÕES SOBRE O ENSINO
}

\author{
Joelma Nogueira dos Santos ${ }^{1}$, Ana Carolina Costa Pereira C $^{2,3}$ \\ ${ }^{1}$ Instituto Federal de Educação, Ciência e Tecnologia do Ceará (IFCE) \\ ${ }^{2}$ Programa de Pós-graduação em Ensino de Ciências e Matemática \\ ${ }^{3}$ Universidade Estadual do Ceará \\ <joelma.santos@ifce.edu.br>, <carolina.pereira@uece.br>
}

DOI: $10.21439 /$ conexoes.v9i4.919

\begin{abstract}
Resumo. O mundo atualmente vem passando por transformações afetando, sobretudo o âmbito escolar. Espaço esse, em que o conhecimento e a sua natureza estão em constante processo de expansão. Nesse sentido, entendemos que os conhecimentos adquiridos na escola são influenciados por essa dinâmica. Com base nisso, podemos dizer que a matemática é uma disciplina que passeia em diversos campos do saber, pois ela, assim como as demais disciplinas que compõem a matriz curricular escolar, faz parte da atividade humana. Por essa razão, tal artigo a priori, evidencia a relevância do Laboratório de Ensino de Matemática (LEM) como um ambiente de aprendizagem, pois, ele possibilita que a teoria e a prática caminhem juntas. Posteriormente o referido trabalho, apresenta considerações sobre a relação entre esse ambiente e a disciplina matemática, e de que forma as experiências de um laboratório de matemática podem contribuir para o melhor aproveitamento da disciplina em questão. Para isso fizemos um levantamento bibliográfico sobre o tema envolvido e relatamos uma experiência vivenciada na educação básica com o LEM. Dessa forma, consideramos que na escola é possível ter um espaço intra ou extraclasse que possa unir os saberes e as competências envolvidas no ensino da referida disciplina.
\end{abstract}

Palavras-chaves: Conhecimento Matemático. Laboratório de Ensino de Matemática. Matemática Escolar. Ensino. Aprendizagem.

\begin{abstract}
The world is currently undergoing transformations affecting, especially, in schools. The space where knowledge and their nature are in constant expansion process. In this sense, we believe that the knowledge acquired at school are affected by this dynamic. Based on this, we can say that mathematics is a discipline that walks in several fields of knowledge, as it, like other disciplines that constitute the school curriculum, is part of human activity. Therefore, this an article a priori, highlights the importance of Mathematics Teaching Laboratory (LEM) as a learning environment because it allows theory and practice go hand in hand. Later, this referred work presents considerations on the relationship between this environment and the mathematics discipline, and how the experiences from a mathematics laboratory can contribute to the better use of the discipline in question. For this, we made a literature review on the involved subject and we reported a experience lived in the basic education with the LEM. Thus, we consider that the school can have an intra or extra-space that can unite the knowledge and skills involved in the teaching of this discipline.
\end{abstract}

Keywords: Mathematical knowledge. Mathematics Teaching Laboratory. School Mathematics. Education. Learning.

\section{INTRODUÇÃO}

Diante dos desafios do mundo contemporâneo que afetam diretamente a educação escolar, professores bus- cam em sua atuação na sala de aula trabalhar com uma matemática mais dinâmica e acessível ao aluno. Para isso, precisam compreender a natureza do conhe- 
cimento matemático e perceber quais caminhos tornam o ensino mais eficaz.

A matemática é vista como uma disciplina de difícil compreensão, em que soluções extensas de problemas, fórmulas complicadas e pouca relação com aplicações no cotidiano fazem parte do seu contexto. Segundo Ponte (1994, p. 2):

\footnotetext{
Para os alunos, a principal razão do insucesso na disciplina de Matemática resulta desta ser extremamente difícil de compreender. No seu entender, os professores não a explicam muito bem nem a tornam interessantes. Não percebem para que serve nem porque são obrigados a estudá-la. Alguns alunos interiorizam mesmo desde cedo uma auto-imagem de incapacidade em relação à disciplina. Dum modo geral, culpam-se a si próprios, aos professores, ou às características específicas da Matemática.
}

Dessa forma, é necessário que o professor de matemática reflita sobre seu fazer pedagógico buscando constantemente preparar-se para os desafios que o ensino atual proporciona. Pois, segundo D'Ambrósio (1991), ainda estamos ensinando matemática em sistemas que não produzem mais resultados satisfatórios. Logo, é necessário refletir sobre novas estratégias que facilitem a compreensão do saber matemático escolar, visto que é na matemática escolar que os saberes são aprendidos. Cabe ao professor buscar a maneira mais adequada para facilitar essa aprendizagem. Por essa razão, o Laboratório de Ensino de Matemática (LEM) está sendo considerado nesse trabalho como uma alternativa viável, que pode contribuir com o processo de ensino e aprendizagem, em que o aluno se torna agente ativo na construção de seu conhecimento. O olhar que traçamos para as considerações apresentadas corresponde com D’Ambrósio (1999), pois ele considera o conhecimento matemático como construção humana.

Nessa perspectiva, esse artigo tem o intuito de apresentar considerações sobre a interação entre laboratório de matemática e a disciplina Matemática ministrada em sala de aula. E de que forma o trabalho desenvolvido em tal espaço (LEM), pode contribuir com a melhoria do desempenho do outro.

\section{1 conhecimento matemático e sua natureza: 0 que devemos buscar?}

O conhecimento matemático que atualmente é estudado na academia, seja ela, no ensino regular básico ou no ensino superior é designado a partir de um momento na evolução da humanidade, em particular, nas origens da matemática nas cidades próximas ao mar mediterrâneo. Esse conhecimento que dominou o mundo moderno, adentrou as civilizações a margem do mundo ocidental, reprimindo a cultura, os costumes e o saber originário de um povo.

Segundo D'Ambrósio (1999, p. 105) o conhecimento é "o conjunto dinâmico de saberes e fazeres acumulados ao longo da história de cada indivíduo e socializado no seu grupo". E todo esse conhecimento, seja ele matemático ou não, está relacionado à história da humanidade.

Nesse sentindo, tal ciência pode ser caracterizada como uma criação humana, pois de acordo com Davis e Hersh (1985) a matemática já foi, está e ainda será desenvolvida, neste caso, pelo homem. Assim como o referido autor, Caraça (2010) nos faz refletir também, sobre o fato do indivíduo utilizar o pensamento matemático em suas atividades diárias independente do mesmo viver isolado, ou seja, ter uma vida primitive 1 , ou morar em um grande centro urbano. De um jeito ou de outro, ele pensa e reflete matematicamente todos os dias. Diante dessa constatação, questionamos: se a matemática é fruto da construção humana, então por que ensinar sobre essa ciência às vezes se torna uma tarefa difícil? $\mathrm{E}$ por que aprendê-la parece algo árduo?

Essas questões correspondem ao que nos propusemos discutir nesse artigo. Mas, para isso precisamos lançar um olhar para indagações relacionadas, sobretudo aos saberes: que matemática temos a intenção de buscar? Devemos lidar com uma matemática que faça raciocinar sobre o sujeito, tendo como referência a perspectiva platônica que desenvolve suas capacidades intelectuais e cognoscitivas? Ou nos fundamentar na visão aristotélica e perceber a matemática mais voltada para as ações do cotidiano? Ou ainda, sob o olhar da visão cartesiana procurar uma matemática que nos sirva de instrumento para entender outras ciências?

No que se refere ao conhecimento matemático e sua natureza, Meneghetti (2004) afirma que precisamos das três concepções para formar e informar o indivíduo, pois elas possibilitam o desenvolvimento, tanto a capacidade de raciocinar de modo indutivo, como também valorizam as ideias sob o aspecto dedutivo. É na escola que a matemática ganha força pedagógica capaz de trabalhar essa três abordagens como mostra a Figura 1.

A Lei de Diretrizes e Bases da Educação Nacional (LDBEN) no 9394/1996 (BRASIL, 1996) trata em seu capítulo II, seção I, Art $22^{\circ}$ que a "educação básica tem por finalidades desenvolver o educando, assegurar-lhe a formação comum indispensável para o exercício da cidadania e fornecer-lhe meios para progredir no traba-

\footnotetext{
${ }^{1}$ Caracterizamos aqui uma vida primitiva na atualidade como aquela na qual o sujeito não direciona o desenvolvimento de suas capacidades cognoscitivas e nem suas habilidades para uma matemática mais formal e aplicada.
} 


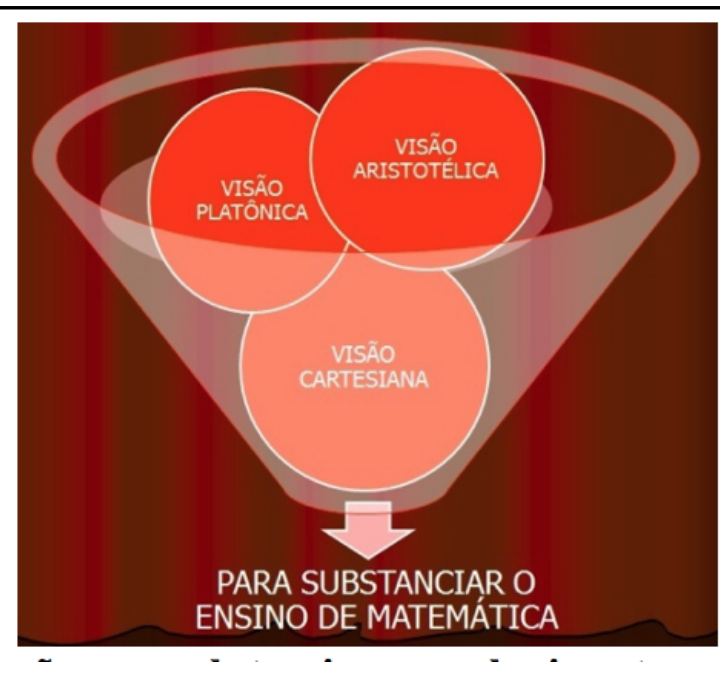

Figura 1: As três concepções que substanciam o conhecimento matemático e sua natureza. Fonte: elaboração dos autores.

lho e em estudos posteriores". A finalidade apresentada pelo documento oficial harmoniza-se com as três concepções que fundamentam o ensino de matemática. Logo, é necessário que o professor compreenda as características intrísicas a tal conhecimento, pois é a partir dela que o docente atua e deve compreender as formas de ministrá-la satisfatoriamente. Mas, qual matemática o professor deve trabalhar em sala e aula?

A seguir apresentamos no Quadro 1 o que acreditamos ser duas vertentes das características da postura do professor em sala de aula.

Quadro 1: Matemáticas trabalhadas pelo professor em sala de aula.

\begin{tabular}{|c|c|}
\hline MATEMÁTICA PRONTA E ACABADA & $\begin{array}{l}\text { MATEMÁTICA COMO CONSTRUÇÃo } \\
\text { HUMANA }\end{array}$ \\
\hline $\begin{array}{l}\text { O ensino se resume à transmissão de } \\
\text { conhecimento } \\
\text { A aprendizagem se resume à recepção de } \\
\text { conhecimento } \\
\text { O método se resume em apresentar definições, } \\
\text { exemplos, teoremas. A repetição é relevante. }\end{array}$ & $\begin{array}{l}\text { - O ensino está na ação de facilitar/mediar a } \\
\text { aprendizagem } \\
\text { A aprendizagem fundamenta-se na } \\
\text { construção do conhecimento pelo aluno } \\
\text { - O método está nas situações didáticas } \\
\text { estabelecidas pelo professor para garantir } \\
\text { interação entre o aluno e o objeto } \\
\text { matemático }\end{array}$ \\
\hline
\end{tabular}

Fonte: elaboração dos autores.

O Quadro 1 nos mostra o papel do professor e o papel do aluno como grandezas inversas, pois exige muito do trabalho do professor para facilitar a aprendizagem do aluno. Enquanto a outra propõe que o trabalho docente seja fácil e rápido, e em relação ao aluno, exige talvez mais esforço, pois a figura do professor como facilitador não aparece.
1.2 O ensino de matemática e o laboratório: o trabalho docente em ação

Ao analisarmos o papel do professor, do aluno e do saber sob a ótica da conexão focalizamos a ideia do triângulo didático de Guy Brousseau ${ }^{2}$ Pommer (2008), o qual descreve como triângulo didático a relação stricto sensu estabelecida por esses três elementos, que envolve a epistemologia do professor, a relação alunosaber e a relação pedagógica. Segundo Pais (2002) esses elementos atuam em determinadas situações e caracterizam a sala de aula como espaço vivo, ou seja, ambiente propicicio à promoção da aprendizagem da matemática.

A relação estabelecida por Brousseau (2008) contribui para que as barreiras epistemológicas e culturais que impedem a transformação do saber científico em saber escolar sejam transpostas. De que forma? Por meio da contextualização e descontextualização do saber. Essa ideia também é defendida por Brasil (1998) quando afirma que

\begin{abstract}
Esse processo de transformação do saber científico em saber escolar não passa apenas por mudanças de natureza epistemológica, mas é influenciado por condições de ordem social e cultural que resultam na elaboração de saberes intermediários, como aproximações provisórias, necessárias e intelectualmente formadoras. É o que se pode chamar de contextualização do saber. Por outro lado, um conhecimento só é pleno se for mobilizado em situações diferentes daquelas que serviram para lhe dar origem. Para que sejam transferíveis a novas situações e generalizados, os conhecimentos devem ser descontextualizados, para serem contextualizados novamente em outras situações. Mesmo no ensino fundamental, esperase que o conhecimento aprendido não fique indissoluvelmente vinculado a um contexto concreto e único, mas que possa ser generalizado, transferido a outros contextos (BRASIL 1998 p. 30).
\end{abstract}

Claramente se percebe uma complexidade nesse contexto, pois não se estagna no aspecto epistemológico apenas. Ela vai além e atinge também o aspecto social e cultural que constituem o processo de transformação do saber científico em escolar. Ou seja, é preciso criar métodos eficazes de ensino que corroborem com as três dimensões apresentadas aqui. Enquanto as teorias metodológicas não saírem do ideário acadêmico e adentrarem as salas de aula, não será tão fácil obter o sucesso escolar. A discussão acerca do processo de ensino para a aprendizagem não é recente. Há muito se questiona o que ainda se caracteriza como obstáculo ao ensino (SAVIANI, 1981).

Muitos são os fenômenos que estão presentes na relação ensino-aprendizagem e que se tornam 'naturais' à

\footnotetext{
${ }^{2}$ Educador matemático francês que desenvolveu a Teoria das Situações Didáticas.
} 
medida que se instalam e permanecem na sala de aula. Dois podem ser destacados aqui por serem comumente apontados nas discussões que cercam o contexto escolar: o péssimo desempenho dos alunos e a má formação docente. Tanto um como o outro promovem o fracasso escolar.

No que se refere ao ensino de matemática, Brasil (1998) aponta alguns fatores que também contribuem para sua atual situação. O documento oficial destaca a compartimentalização dos conteúdos tratados em sala de aula; a desconsideração do conhecimento prévio do aluno pelo professor; a forma equivocada como a História da Matemática e a Resolução de Problemas são tratadas; o não aprofundamento do pensamento da proporcionalidade e da equivalência que permeiam todo o nível básico do ensino da matemática; a falta de recursos didáticos em sala de aula e, a não compreensão e/ou desconhecimento dos professores de matemática sobre a existência dos mesmos.

Lançando um olhar clínico para essas questões, imediatamente se vê a formação inicial dos professores de matemática carecendo de uma estrutura que trabalhe com propostas que resultem numa aprendizagem satisfatória. Analisando os cursos de licenciatura em matemática a partir de uma perspectiva pedagógica, deve-se levar em consideração a ideia de capacitar pessoas para atuar em diferentes níveis de escolaridade da educação básica. Embora, o currículo tradicional tenha sofrido algumas mudanças nos últimos anos e novas propostas já são trabalhadas no intuito de possibilitar uma aprendizagem significativa, ainda é possível ver, por exemplo, a aritmética, a geometria e a álgebra elementar, desconectadas entre si e trabalhadas sem nenhuma relação com o cotidiano do aluno ou com outras áreas de conhecimento.

Segundo Moreira e David (2005, p. 20), a matemática precisa ser considerada "historicamente em conjunção com a prática e a cultura escolar". Porém, a realidade de nossas escolas ainda caminha lentamente para uma mudança significativa. As avaliações em larga escala como Saeh ${ }^{3}$ por exemplo, funcionam como termômetros e nos dão um diagnóstico dos avanços e dos retrocessos do ensino.

Nesse aspecto, os resultados do IDEB (Índice de Desenvolvimento da Educação Básica) do Brasil de 2013, calculado a partir do censo escolar e das médias dessas avaliações, e suas respectivas metas nos dão uma mostra de como tem se dado o desempenho dos alunos

\footnotetext{
${ }^{3}$ Sistema de Avaliação da Educação Básica composta por três avaliações externas: ANEB (Avaliação Nacional da Educação Básica), ANRESC/Prova Brasil (Avaliação Nacional do Rendimento Escolar) e ANA (Avaliação Nacional da Alfabetização).
}

em níveis de ensino.

A Figura 2 nos mostra que nos anos finais do ensino fundamental e no ensino médio ainda há muito que fazer para atingir as metas. A esse respeito levantamos os seguintes questionamentos: no contexto do ensino de matemática, o que está sendo feito para mudar essa realidade? Como o professor pode desenvolver sua prática de maneira que possibilite uma mudança nas estatísticas dos últimos anos?

\section{IDEB - Resultados e Metas}

IDEB 2005, 2007, 2009, 2011, 2013 e Projeções para o BRA SIL

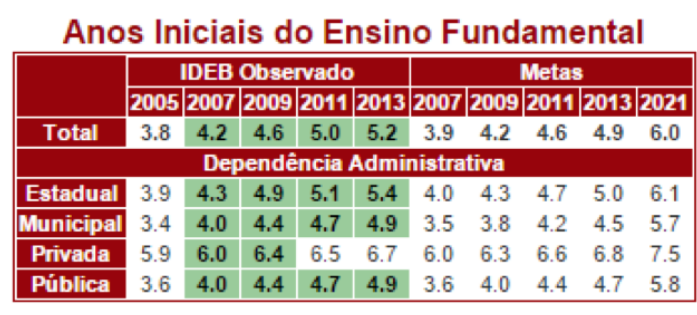

Anos Finais do Ensino Fundamental

\begin{tabular}{|c|c|c|c|c|c|c|c|c|c|c|}
\hline & \multicolumn{5}{|c|}{ IDEB Observado } & \multicolumn{5}{|c|}{ Metas } \\
\hline & 2005 & 2007 & 2009 & 2011 & 2013 & 2007 & 2009 & 2011 & 2013 & 2021 \\
\hline Total & 3.5 & 3.8 & 4.0 & 4.1 & 4.2 & 3.5 & 3.7 & 3.9 & 4.4 & 5.5 \\
\hline \multicolumn{11}{|c|}{ Dependência Administrativa } \\
\hline Estadual & 3.3 & 3.6 & 3.8 & 3.9 & 4.0 & 3.3 & 3.5 & 3.8 & 4.2 & 5.3 \\
\hline Municipal & 3.1 & 3.4 & 3.6 & 3.8 & 3.8 & 3.1 & 3.3 & 3.5 & 3.9 & 5.1 \\
\hline Privada & 5.8 & 5.8 & 5.9 & 6.0 & 5.9 & 5.8 & 6.0 & 6.2 & 6.5 & 7.3 \\
\hline Pública & 3.2 & 3.5 & 3.7 & 3.9 & 4.0 & 3.3 & 3.4 & 3.7 & 4.1 & 5.2 \\
\hline \multicolumn{11}{|c|}{ Ensino Médio } \\
\hline & \multicolumn{5}{|c|}{ IDEB Observado } & \multicolumn{5}{|c|}{ Metas } \\
\hline & 2005 & 2007 & 2009 & 2011 & 2013 & 2007 & 2009 & 2011 & 2013 & 2021 \\
\hline Total & 3.4 & 3.5 & 3.6 & 3.7 & 3.7 & 3.4 & 3.5 & 3.7 & 3.9 & 5.2 \\
\hline \multicolumn{11}{|c|}{ Dependência Administrativa } \\
\hline Estadual & 3.0 & 3.2 & 3.4 & 3.4 & 3.4 & 3.1 & 3.2 & 3.3 & 3.6 & 4.9 \\
\hline Privada & 5.6 & 5.6 & 5.6 & 5.7 & 5.4 & 5.6 & 5.7 & 5.8 & 6.0 & 7.0 \\
\hline Pública & 3.1 & 3.2 & 3.4 & 3.4 & 3.4 & 3.1 & 3.2 & 3.4 & 3.6 & 4.9 \\
\hline
\end{tabular}

Figura 2: IDEB 2013 resultados e metas Fonte: Instituto Nacional de Estudos e Pesquisas Educacionais Anísio Teixeira (INEP).

Segundo Brasil (2001a, p. 4), há três características inerentes à atividade docente: "orientar e mediar o ensino para a aprendizagem dos alunos [...]; desenvolver práticas investigativas [...]; utilizar novas metodologias, estratégias e materiais de apoio”. Ele aponta que a atuação docente tem um caráter dinâmico e objetivo, sobretudo no que se refere à Educação Básica, pois é apartir dela, que os educandos iniciam o processo de apropriação dos conhecimentos matemáticos. Em relação à formação inicial do professor, o Brasil 2001b p. 3-4) apresenta as competências e habilidades que o docente de matemática deve desenvolver na sua formação inicial e ao longo de sua atuação docente:

No que se refere às competências e habilidades próprias 
do educador matemático, o licenciado em Matemática deverá ter as capacidades de: a) elaborar propostas de ensino-aprendizagem de Matemática para a educação básica; b) analisar, selecionar e produzir materiais didáticos; c) analisar criticamente propostas curriculares de Matemática para a educação básica; d) desenvolver estratégias de ensino que favoreçam a criatividade, a autonomia e a flexibilidade do pensamento matemático dos educandos, buscando trabalhar com mais ênfase nos conceitos do que nas técnicas, fórmulas e algoritmos; e) perceber a prática docente de Matemática como um processo dinâmico, carregado de incertezas e conflitos, um espaço de criação e reflexão, onde novos conhecimentos são gerados e modificados continuamente; f) contribuir para a realização de projetos coletivos dentro da escola básica (BRASIL 2001b p. 3 - 4).

Queremos ressaltar aqui duas competências que são pertinentes ao tema em questão: a competência apresentada no item $b$, que aponta o professor como capaz de analisar, selecionar e produzir material didático, o que inclui também recursos de caráter manipulativo; e a proposta do item d, que vem se harmonizar com a ideia de Pavanello (2003) quando afirma que o método deve predominar sobre o conteúdo o qual as pessoas precisam pensar sobre o que fazem matematicamente, assim como, também, estabelecer relações com o cotidiano em que os educandos estão inseridos. Mas, eis a questão sobre, onde obter mecanismos para fazer com que essas interações sejam desenvolvidas no ensino de Matemática?

Brasil (1998) diz que há caminhos que facilitam a aprendizagem da disciplina em questão, porém, é necessário que o professor seja familiarizado com as metodologias de ensino, e além de tudo, saiba discernir quais delas podem ser trabalhados em sala de aula para dinamizar e enriquecer a disciplina ministrada. Pereira e Vasconcelos (2006) apontam: a Etnomatemática, a Modelagem Matemática, a História da Matemática, os recursos tecnológicos, os jogos matemáticos como sendo algumas dessas trajetórias, ou seja, como possibilidades de trabalho para o professor desenvolver sua prática. Nesse aspecto surge outro questionamento: como trilhar esses caminhos?

Lorenzato (2006) sugere maneiras de como o professor pode atuar no caminho que escolher. Começar o conteúdo de sala trabalhando com material concreto é uma delas. Outra forma importante apontada pelo autor é reconhecer e identificar as contribuições conceituais dos alunos, como valorizar seus erros, propiciar a experimentação e favorecer a descoberta. O professor pode ainda explorar as aplicações da matemática, ensinar integradamente a aritmética, a álgebra e a geometria. E por fim, construir o Laboratório de Ensino de Matemática (LEM) considerado como ambiente de aprendizagem que inicialmente pode ser estruturado na própria sala de aula.

O LEM pode ser entendido como um armário ou um
canto de sala onde são depositados os materiais didáti-
cos específicos ao ensino de matemática. Quando pos-
sível essa concepção deve ser ampliada para uma sala-
ambiente que além de abrigar materiais, tem por obje-
tivo a estruturação, organização, planejamento e execu-
ção das atividades matemáticas. Assim, facilita-se, prin-
cipalmente ao aluno, o questionamento, a experimenta-
ção a análise, isto é, a construção de seu conhecimento
(LORENZATO 2006 p. 111).

Nesse sentido, as atividades de investigação e experimentação proporcionam ao professor explorar a bagagem de conhecimento do aluno e considerá-lo como sujeito ativo no processo de aprendizagem. Essas ações podem ser desenvolvidas no LEM porque é um ambiente que propicia a compreensão das ideias matemáticas. Sua construção deve ser coletiva, ou seja, todos os segmentos da escola devem estar envolvidos. Isso porque o laboratório é considerado por Lorenzato (2010) o centro da vida matemática na escola e com certeza auxilia na relação entre a matemática escolar e a matemática do cotidiano. De acordo com Santos (2013) é nesse contexto que o professor deve atuar.

\footnotetext{
O ambiente necessário para a construção de uma visão de Matemática conforme proposta pelos construtivistas caracteriza-se por um ambiente em que os alunos propõem, exploram e investigam problemas matemáticos. Esses problemas provêm tanto de situações reais (modelagem) como de situações lúdicas (jogos e curiosidades matemáticas) e de investigações e refutações dentro da própria Matemática [...] O ambiente proposto é um ambiente positivo que encoraja os alunos a propor soluções, explorar possibilidades, levantar hipóteses, justificar seu raciocínio e validar suas próprias conclusões. Respostas incorretas constituem a riqueza do processo de aprendizagem e devem ser exploradas e utilizadas de maneira a gerar novo conhecimento, novas questões, novas investigações ou um refinamento das idéias existentes (D'AMBRÓSIO 1993 p. 37).
}

É assim que o LEM deve funcionar, tanto na Educação Infantil, como no Ensino Fundamental ou ainda no Ensino Médio. O que realmente importa nas aulas de matemática é utilizar instrumentos que impulsionem o aluno a trabalhar com o método indutivo e dedutivo, com estimativas e experimentações, assim como, o domínio da argumentação de forma que promova debates eficazes para desenvolvimento de habilidades, envolvendo o raciocínio, o agir individual e em grupo. Com capacidade para avaliar as ações coletivas e individuais do educando, levando-o a refletir sobre os processos relacionados ao conhecimento que esta sendo problematizado.

O Laboratório de Ensino de Matemática tem condições suficientes para suprir essa necessidade, uma vez 
que, o LEM apresenta potencialidades como: diagnosticar o nível de desempenho dos alunos, e a dosagem seriada de conteúdos, porém, exige muito trabalho e planejamento do professor podendo correr o risco de ser mal utilizado, até porque nem tudo vira prática de laboratório. Nesse sentido, determinadas metodologias requerem um alto custo financeiro, pois exigem o uso de materiais didáticos caros, importantes para o laboratório, principalmente os manipuláveis. De acordo com Pais (2013) a intenção é que as atividades tenham condições de abstrair o pensamento matemático utilizando recursos didáticos em que

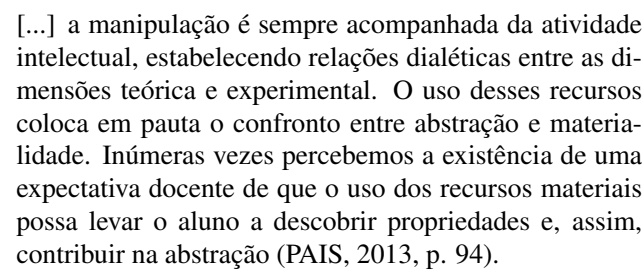
intelectual, estabelecendo relações dialéticas entre as dimensões teórica e experimental. O uso desses recursos coloca em pauta o confronto entre abstração e materialidade. Inúmeras vezes percebemos a existência de uma expectativa docente de que o uso dos recursos materiais possa levar o aluno a descobrir propriedades e, assim, contribuir na abstração (PAIS. 2013 p. 94).

Dessa forma, o LEM é um espaço na escola que deve ser utilizado para construir o conhecimento matemático do aluno, levando-o a estudar concomitantemente a teoria em conjunto com a prática, assimilando conceitos de forma significativa. Dependendo da fase cognitiva dos alunos, os materiais disponíveis no LEM podem ajudar na abstração melhorando a aprendizagem e desmistificando que a matemática é uma disciplina de 'difícil' compreensão.

\subsection{O LEM na escola de educação básica: um mé- todo alternativo}

Uma das propostas para a existência do LEM na escola é a de contribuir com o trabalho do professor de matemática em atividades que relacionem a teoria com a prática, formando conceitos, desenvolvendo o domínio das técnicas operatórias e explorando situações em que o saber se aplica. A ideia é envolver o que Lima (1999) apresenta com conceituação, manipulação e aplicação.

E a partir dos três componentes apresentados na Figura 3. é possível traçar uma lista de atividades de investigação visando à construção do conhecimento matemático que podem ser desenvolvidas no LEM. Dentre elas destacamos:

- Práticas complementares dos conteúdos desenvolvidos em sala de aula;

- Sessões de filmes e o clube da matemática;

- Reuniões bimestrais com os professores;

- Planejamento semanal dos professores de matemática;

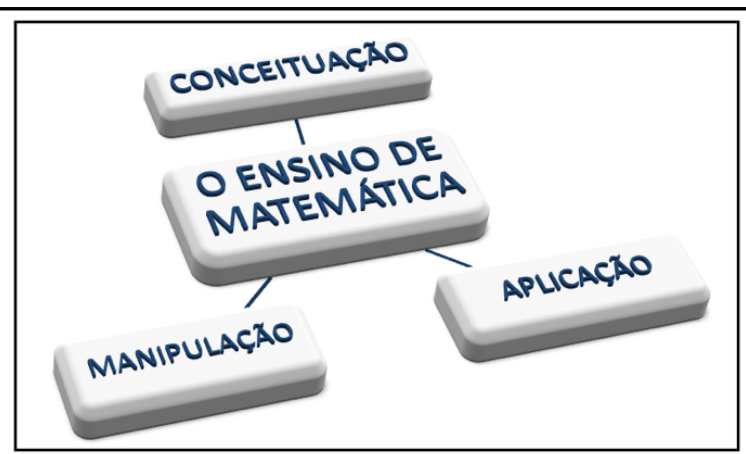

Figura 3: Os três componentes do ensino de matemática segundo Lima (1999). Fonte: Elaboração dos autores.

- Monitoria de matemática;

- Intervenção pedagógica para alunos do ensino fundamental e médio com déficit de aprendizagem da matemática;

- Atividades voltadas para as avaliações em larga escala;

- Projetos de leitura e escrita matemática;

- Oficinas de produção de material didático.

Em nossa investigação percebemos que a teoria das situações didáticas foi a que melhor se aplicou às atividades trabalhadas no LEM, pois os tipos de situações propostas na visão de Brousseau (2008) efetivamente nos auxiliaram na busca dos resultados que esperávamos.

Entendemos que o LEM se caracteriza como um ambiente de aprendizagem que auxilia a relação teoriaprática assim como reforça o papel de cada elemento constituinte no processo de ensino para a aprendizagem: o professor, o aluno e o saber. As práticas desenvolvidas foram suficientes e favoráveis às ações que, de forma implícita ou explicíta, iam se desenvolvendo para a constituição do saber matemático escolar. Segundo Pais (2002, p. 65), as situações didáticas podem ser compreendidas como as "múltiplas relações pedagógicas estabelecidas entre o professor, os alunos e o saber, com a finalidade de desenvolver atividades voltadas para o ensino e para a aprendizagem de um conteúdo específico". Colocamos aqui de maneira suscinta o desenrolar das situações didáticas que fundamentaram nossa pesquisa.

O primeiro tipo de situação didática apresentada por Brousseau (2008) é a devolução. Nela, compartilhamos com os alunos a responsabilidade da relação ensino-aprendizagem do conteúdo explorado específico 
de cada aula prática. Os alunos foram inseridos no contexto do conteúdo específico auxiliados pelo milieu que segundo Teixeira e Passos (2013, p. 160), é caracterizado como o meio em que ocorre a aprendizagem, podendo esse ser material, mas que não exprime explicitamente a intenção didática.

$$
\begin{aligned}
& \text { [...] um dispositivo deve ser colocado em ação para que } \\
& \text { uma pessoa ensine um conhecimento e controle a sua } \\
& \text { aquisição. Tal dispositivo compreende um milieu mate- } \\
& \text { rial: peças de um jogo, uma prova, um problema, uma } \\
& \text { ficha, e regras de interações do aprendiz com aquele dis- } \\
& \text { positivo - no caso, o jogo propriamente dito (BROUS- } \\
& \text { SEAU, } 1986 \text { apud TEIXEIRA; PASSOS, 2013, p. 160). }
\end{aligned}
$$

Diante da apresentação do milieu, surgia em cada prática a segunda situação didática: a ação. Nesse momento os alunos refletiam sobre o que deveriam executar em busca de um resultado. Ao interagir com o milieu os alunos passavam a tomar decisões no intuito de organizar a resolução do problema que lhes era proposto.

$\mathrm{Na}$ ação viam-se claramente os alunos colocando seus conhecimentos em prática, embora não estivessem matematicamente definidos e estruturados. Para que isso acontecesse, seria necessário avançar na sequência das situações didáticas. E foi o que fizemos. Levamos os alunos para a formulação, o tipo de situação que ocorre logo após a ação. Com a ajuda do milieu os alunos iam discutindo entre si sobre os caminhos utilizados para resolver a situação-problema apresentada no início da prática. Nessa fase os alunos já estavam conscientes do problema proposto, porém, ainda não se viam na obrigação de apresentar uma linguagem matemática mais adequeda. Daí a existência de "ambiguidade, redundância, uso de metáforas, criação de termos semiológicos novos, falta de pertinência e de eficácia" (POMMER, 2008, p. 7).

Na validação, situação que segue logo após a formulação, os alunos justificavam com convencimento o que formulavam, dessa vez utilizando-se de uma linguagem matemática apropriada para mostrar que suas descobertas estavam corretas. As descobertas iam se moldando e se estruturando nesses quatro tipos de situações didáticas nas quais os alunos tinham orientação. Vale ressaltar que, nas etapas os alunos demonstravam autonomia na resolução da atividade.

Para finalizar o trabalho em cada aula prática, nos apoiávamos na institucionalização, situação didática proposta por Brousseau (2008) na qual o processo de descoberta termina. Nosso papel entrava em ação e nesse momento tomávamos novamente a responsabilidade da relação ensino-aprendizagem compartilhada e íamos conduzindo os alunos na retenção de determinadas justificativas e na eliminação do que não iria servir para a constituição do saber. A institucionalização permite ao professor constatar se os alunos aprenderam de fato, pois a formalização e a generalização do objeto matemático envolvido na atividade ocorrem nessa situação didática.

Vivenciamos essa experiência em uma escola pública estadual do Ceará. Destacamos aqui alguns conteúdos trabalhados com as práticas do LEM como atividade complementar ao trabalho docente em sala de aula e que envolveram a teoria das situações didáticas de Guy Brousseau.

- Números negativos;

- Álgebra: monômio e polinômios;

- Álgebra: produtos notáveis;

- Geometria espacial;

- Geometria plana: semelhança de figuras geomátircas, teorema de Tales, teorema de Pitágoras;

- Trigonometria: razões trigonométricas, ciclo trigonométrico.

A maioria dos materiais utilizados para demonstrar a importância do LEM, pode ser encontrada nas escolas públicas do Brasil. Outros foram confeccionados pelos alunos. Entretanto, ressaltamos que existe uma necessidade de confecção de materiais concretos para conteúdos que são ministrados nos anos finais do Ensino Fundamental, Ensino Médio e Ensino Superior. Poucos são aqueles que objetivam para uma prática nesses seguimentos justamente pelo fato de não saberem como, por que e nem quando utilizar o material didático mesmo as discussões a respeito dessa temática acontecendo há algum tempo em âmbito acadêmico. Nessa perspectiva, entendemos que tentar trabalhar o laboratório como uma metodologia de ensino é a maneira adequada de garantir um ensino inovador e eficaz.

Nesse contexto, podemos perceber que o LEM não se apoia, apenas no material concreto, pois é possível também, o uso de vídeos como um recurso a facilitação da aprendizagem. A intenção é propiciar ao aluno a oportunidade ter acesso aos conteúdos matemáticos por meio dos videos, o que consequentemente pode facilitar a visualizacão de conteúdos problematizados em sala de aula.

\section{Discussões Finais}

A era do conhecimento tem trazido oportunidades e desafios que vão desde situações do cotidiano, até aqueles relacionados ao ambiente de sala de aula, lugar esse 
onde se projeta as primeiras aprendizagens formais no indivíduo. Sendo assim, vale salientar que os conhecimentos historicamente acumulados, dentre eles, a matemática é uma ciência que se faz presente tanto no diaa-dia, quanto na academia e se torna indispensável na formação do indivíduo.

Por essa razão, a matemática relaciona-se com várias áreas do saber. Ela entra na sala de aula de uma forma, ainda pouco convencional, desafiando o professor a buscar métodos, técnicas e recursos didáticos que superem os obstáculos trazidos na própria história curricular da matemática. De encontro a isso, o Laboratório de Ensino de Matemática é um local onde a teoria e a prática, dialogam, possibilitando que a abstração e o entendimento de determinados conceitos matemáticos sejam compreendidos pelos alunos.

Devemos considerar que a dinâmica de uma sala de aula deve ser pensada e planejada de forma que investigações sobre as práticas possam auxiliar no aprimoramento de metodologias que visem à aprendizagem do aluno. Nesse ponto devemos entender a relevância dos professores como atores importantes diante do processo de ensino e aprendizagem, sobretudo, por exemplo, no que se refere à decisão necessária para conduzir as aulas. A eles cabem às escolhas sobre métodos, técnicas e recursos que deverão ser utilizados.

Tão importante quanto os demais aspectos evidenciados nesse artigo, vale ressaltar sobre a importância das discussões de cunho teórico e prático, referentes à inserção da tecnologia no ensino e pesquisa, às potencialidades didático-pedagógicas dos jogos e materiais manipulativos, de vídeos, além de outros recursos didáticopedagógicos, os quais deverão fazer parte das atividades práticas desenvolvidas (cursos) e do referencial teórico a ser discutido, de maneira multimodal, em virtude das distintas formas de interlocução no século XXI, comunicação e interação de ambientes que hospedam cursos à distância e/ou que apoiam cursos presenciais.

Outras pesquisas de cunho teórico ou empírico devem ser realizadas com o intuito de discutir mais sobre essas relações que são vivenciadas na matemática escolar. Muitas dessas discussões estão no "chão da sala de aula”, prontas para serem coletadas e tratadas. Basta que o professsor-pesquisador mobilize no seu ambiente escolar a ação, a discussão, a reflexão e consequentemente a aprendizagem de forma que integre os diversos lugares, dando espaço para que o Laboratório de Ensino de Matemática faça parte desse contexto.

\section{REFERÊNCIAS}

BRASIL. A Lei de Diretrizes e Bases da Educação Nacional (LDBEN) $n^{\circ}$ 9394/1996. Brasília:
Ministério da Educação, 1996. Disponível em: <http://portal.mec.gov.br/arquivos/pdf/ldb.pdf> Acesso em: 22 set. 2015.

Parâmetros Curriculares Nacionais: matemática. Brasília: Ministério da Educação, 1998.

Parecer CNE/CES no 009/2001, de 08 de maio de 2001a. Trata das Diretrizes Curriculares Nacionais para a Formação de Professores da Educação Básica, em nível superior, curso de licenciatura, de graduação plena. Brasília: Ministério da Educação, 2001a. Disponível em: $<$ http://portal.mec.gov.br/cne/arquivos/pdf/009.pdf> Acesso em: 08 out. 2015.

Parecer CNE/CES $n^{\circ} 1302 / 2001$, de 06 de novembro de 2001b. Trata das Diretrizes Curriculares Nacionais para os Cursos de Matemática, Bacharelado e Licenciatura. Brasília: Ministério da Educação, 2001b. Disponível em: <http: //portal.mec.gov.br/cne/arquivos/pdf/CES13022.pdf> Acesso em: 08 out. 2015.

BROUSSEAU, G. Fondements et methodes de la didactique des mathematiques', recherches en didactique des mathématiques. Grenoble, v. 7, n. 2, p. $33-116,1986$.

Introdução ao estudo das situações didáticas: conteúdos e métodos de ensino. São Paulo: Ática, 2008.

CARAÇA, B. J. Conceitos fundamentais de matemática. 7. ed. Lisboa: Gradiva, 2010.

DAVIS, P. J.; HERSH, R. Experiencia matemática. Rio de Janeiro: F. Alves, 1985.

D’AMBRÓSIO, B. S. Formação de professores de matemática para o século XXI: o grande desafio. Proposições, Unicamp, Campinas, v. 4, n. 1, p. 35-41, mar. 1993.

D’AMBRÓSIO, U. Matemática, ensino e educação: uma proposta global. Temas \& Debates, SBEM, Rio Claro, v. 4, n. 3, p. 1 - 16, 1991.

A história da matemática: questões historiográficas e políticas e reflexos na educação matemática. In: BICUDO, M. A. V. (Ed.). Pesquisa em educação matemática: concepções e perspectivas. São Paulo: Unesp, 1999. p. 97-115.

LIMA, E. L. Conceituação, manipulação e aplicações. RPM - Revista do Professor de Matemática, São Paulo, v. 41, p. $1-6,1999$. 
LORENZATO, S. A. Para aprender matemática. Campinas: Autores Associados, 2006.

O laboratório de ensino de matemática na formação de professores. 3. ed. Campinas: Autores Associados, 2010.

MENEGHETTI, R. C. G. O realismo e o idealismo: focalizando o conhecimento matemático. In: MARTINS, R. A.; MARTINS, L. A. C. P.; SILVA, C. C.; FERREIRA, J. M. H. (Ed.). Filosofia e história da ciência no Cone Sul: 3 o Encontro. Campinas: AFHIC, 2004. p. $371-377$.

MOREIRA, P. C.; DAVID, M. M. M. S. Formação matemática do professor: licenciatura e prática docente escolar. Belo Horizonte: Autêntica Editora, 2005. Coleção tendências em educação matemática, 11.

PAIS, L. C. Didática da Matemática: uma análise da influência francesa. 2. ed. Belo Horizonte: Autêntica Editora, 2002.

Ensinar e aprender matemática. 2. ed. Belo Horizonte: Autêntica Editora, 2013.

PAVANELLO, R. M. A pesquisa na formação de professores de matemática para a escola básica. In: SBEM. Educação Matemática em Revista. São Paulo, 2003. v. 10 , n. 15 , p. 8-12.

PEREIRA, A. C. d. C.; VASCONCELOS, C. B. Educação matemática: concepções sobre o ensino e aprendizagem em matemática. Rematec - Revista de Matemática, Ensino e Cultura, UFRN, Natal, n. 1, p. 9-16, jul. 2006.

POMMER, W. M. Brousseau e a idéia de situação didática. In: SEMA-Seminários de Ensino de Matemática. São Paulo: FEUSP, 2008. Disponível em: <http://www.nilsonjosemachado.net/sema20080902. pdf $>$ Acesso em: 13 set. 2015.

PONTE, J. P. da. Matemática: uma disciplina condenada ao insucesso? NOESIS, n. 32, p. 2, 1994.

SANTOS, J. N. d. A construção do conceito de número natural e o uso das operações fundamentais nas séries iniciais do ensino fundamental: uma análise conceitual. Dissertação (Mestrado Profissional em Ensino de Ciências e Matemática) - Centro de Ciências, Universidade Federal do Ceará, Fortaleza, 2013.
SAVIANI, D. Escola e democracia. 4. ed. São Paulo: Editores Associados, 1981. Disponível em: <https://gepelufs1.files.wordpress.com/2011/05/ escola-e-democracia-dermeval-saviani.pdf $>$. Acesso em: 05 out. 2015.

TEIXEIRA, P. J. M.; PASSOS, C. C. M. Um pouco da Teoria das Situações Didáticas (TSD) de Guy Brousseau. Zetetiké: Revista de Educação Matemática, Campinas, v. 21, n. 39 , 2014. ISSN 2176-1744. Disponível em: <http: //ojs.fe.unicamp.br/ged/zetetike/article/view/4327>. 